\title{
Religi Masyarakat Periferi: Analisis Rites of Passage Atas Ruwatan Rambut Gimbal di Dieng
}

\author{
Ustadi Hamsah \\ Universitas Islam Negeri Sunan Kalijaga, Yogyakarta, Indonesia \\ email: ustadi.hamsah@uin-suka.ac.id
}

\begin{abstract}
This article aims to see the traditions associated with the existence of the Absolute which will give birth to a unique and distinctive ritual system in the ritual of ruwatan dreadlocks in Dieng. Perception of myths and cultural phenomena with a sublimated perspective and is an innovation for the central tradition in the Ngayogyokarto Hadiningrat Palace. There was a "movement" of the central culture that pulled over (periphery) and manifested itself into a "religious" ritual carried out by the community. The problem that arises is how the ritual tradition of ruwatan dreadlocks is interpreted as a religiosity that is not practiced in the palace, as well as what it means for the people of Dieng. Data were collected using participatory observation methods, in-depth interviews, document studies, and focus group discussions. The analysis uses techniques of deep analysis by applying the perspective rites of passage from Arnold van Gennep and Victor Turner. The result and analysis are that there is a positive compromise between the concept of holiness and more worldly concepts such as economic interests (tourism) which is a form of cultural reaggregation in Dieng.
\end{abstract}

Keywords: Dieng, periphery, rambut gimbal (clump hair), rites of passage

\begin{abstract}
Abstrak
Artikel ini bertujuan untuk melihat tradisi yang terkait dengan eksistensi Yang Maha Mutlak akan melahirkan sistem ritual yang unik dan khas pada ritual ruwatan rambut gimbal di Dieng, yang merupakan wilayah terpencil dan periferi dari tradisi dan budaya Jawa yang berpusat di Kraton Ngayogyokarto Hadiningrat. Mempersepsi mitos dan fenomena budaya dengan cara pandang yang mengalami sublimasi dan merupakan inovasi bagi tradisi pusat di kraton. Terjadi "gerak" budaya pusat yang menepi (periferi) dan termanifestasi menjadi sebuah ritual "religius" yang dilakukan oleh masyarakat. Persoalan yang muncul
\end{abstract}


adalan bagaimana tradisi ritual ruwatan rambut gimbal dimaknai sebagai sebuah religiusitas yang tidak dilakukan di pusat tradisi (kraton), serta bagaimana makna bagi masyarakat Dieng. Dengan menggunakan perspektif rites of passage artikel berikut ini menguraikan fenomena tersebut. Hasil dan analisis adalah adanya kompromi positif antara konsep kesucian dengan konsep-konsep yang lebih duniawi seperti kepentingan ekonomi (pariwisata) yang merupakan bentuk reagregasi budaya di Dieng.

Kata kunci: Dieng, periferi, rambut gimbal, ritus peralihan

\section{Pendahuluan}

Masyarakat manusia terbentuk dari kolektifitas individu-individu yang berada di dalamnya. Elan yang menjadi landasan kehidupan sebuah masyarakat adalah sistem budaya yang melekat di dalamnya. Tanpa ada sistem budaya kehidupan masyarakat manusia akan bersifat fragile dan mudah punah. Budaya dalam sebuah masyarakat dimaknai sebagai sebuah sistem gagasan yang kemudian dituangkan dalam bentuk institusi-institusi budaya. Merujuk pada salah satu pandangan ilmuan, kebudayaan memiliki, paling tidak, tujuh unsur, yakni budaya pikir (sistem religi, sistem pengetahuan, sistem kemasyarakatan), budaya materi (sistem teknologi dan peralatan, sistem pencaharian), dan budaya bahasa (sistem bahasa, sistem kesenian).

Munculnya sistem kebudayaan itu karena manusia berupaya memenuhi kebutuhan-kebutuhan hidupnya. Malinoswki menyebutkan bahwa manusia memiliki tingkatan-tingkatan budaya, dari yang paling dasar sampai yang paling kompleks. Pemenuhan atas kebutuhan-kebutuhan tersebut memunculkan sistem-sistem budaya. Sistem budaya pikir dalam konteks tertentu, menjadi sistem nilai yang melandasi kehidupan masyarakat, terutama sistem religi. Sistem religi merupakan ungkapan simbolik keyakinan manusia atas The Supreme Being dalam konteks culture and climate tertentu. Hal ini menyebabkan ungkapan simbolik atas satu fenomena religius berbeda antara konteks satu dengan lainnya.

Sebagai sistem kebudayaan, religi menjadi sistem yang paling kompleks karena memuat kesadaran-kesadaran non materiil yang sangat subjektif (Williams, 2005, hal. 97). Kesadaran ini pun bertambah kompleks ketika dalam sistem religi "dihadirkan" di dalamnya konsep-konsep kesucian yang tidak saja terkait dengan unsur subjektif manusia, namun juga terkait dengan "subjek lain" yang berada di luar diri manusia. Terkait dengan hal ini Clifford Geertz menjelaskan sistem religi sebagai berikut,

A religion is (1) a system of symbols which acts to (2) establish powerful, pervasive, and long-lasting moods and motivations in men by (3) 
formulating conceptions of a general order of existence and (4) clothing these conceptions with such an aura of factuality that (5) the moods and motivations seems uniquely realistic (Geertz, 1966, hal. 4; Lambek, 2002, hal. 63).

Penjelasan interpretif dari Geertz ini menegaskan bahwa agama sebagai sistem budaya merupakan sebuah unsur yang fundamental dalam masyarakat manusia. Hal ini ditegaskan bahwa agama merupakan "a source of ultimate meaning, binding together diverse social and cultural elements, and potentially providing solidarity and identity"(Williams, 2005). Pandangan ini sejatinya merupakan gagasan untuk menegaskan bahwa agama merupakan cultureencompassing significance. Atas dasar gagasan ini agama dimaknai sebagai sistem nilai (value system-system of meaning) yang fundamental. Apa yang dilakukan oleh Geertz dalam menjelaskan sistem religi sebagai sistem budaya merupakan alternatif pemikiran dari gagasan-gagasan yang telah ada sebelumnya. Mengacu pada penjelasan Maciej Potz, pendekatan terhadap agama dibagi menjadi dua, yakni teologis dan non-teologis. Pendekatan teologis menekankan pada sistem doktrin, kultus, ritus, dan lain sebagainya, sedangkan pendekatan non-teologis lebih menekankan pada struktur dan fungsi fenomena keagamaan dalam konteks sosial (Potz, 2020, hal. 23). Dalam hal ini, Geertz lebih mendekati agama dari aspek non-teologis karena melihat agama sebagai sistem simbol dan fungsi-fungsinya.

Di antara gagasan tersebut adalah etnometodologi dari Harold Garfinkel, Herbert Blumer dengan "second Chicago school"-nya mengintroduksi gagasan interaksionisme simbolik, demikian juga generasi kedua Frankfurt School di antaranya Jurgen Habermas yang menegaskan keterikatan antara budaya dan makna dalam teori "komunikasi efektif" -nya (Williams, 2005).

Terkait dengan penjelasan di atas, Peter Berger menegaskan bahwa sistem religi merupakan sacred canopy bagi kehidupan masyarakat (Berger, 1966, hal. 11-211). Sistem religi menjadi determinasi bagi kehidupan masyarakat. Konsep-konsep kesucian yang telah diungkapkan secara simbolik dalam manifestasi unsur-unsur kebudayaan sebagaimana dijelaskan di atas dimaknai sebagai paramount yang menaungi seperti canopy dari sistem nilai manusia. Sistem nilai ini pada akhirnya melahirkan konsep-konsep simbolik, misalnya sacred space. Konsep ini mengacu pada gagasan tentang kesucian dalam fenomena sistem religi seperti dijelaskan di atas, yakni kebudayaan dan konteks (Smith, 2008, hal. 5-10). Konsep kesucian (das heligie (Otto, 1923), 
numinus-Mircea Eliade (1961), atau locus sanctus) selalu dimanifestasikan dalam bentuk-bentuk simbolik pada benda, tempat, waktu, ide, dan lain sebagainya.

Salah satu bentuk ungkapan atas konsep kesucian itu adalah ritual. Aspek-aspek yang terkait dengan ritual selalu bersifat sanctus (suci). Ritualritual yang dilakukan oleh komunitas tertentu bertransformasi menjadi sistem gagasan lain misalnya initiation (peralihan). Proses initiation secara teoritis terstruktur menjadi tiga tahap. Arnold van Gennep dan Victor Turner menyebutkan ketiga tahap tersebut di antaranya adalah preparation, liminal, dan reagregation (Turner, 1991). Turner lebih fokus pada penjelasan tentang konsep liminal, sementara Van Gennep lebih umum pada konsep ritualnya (rites) (Arnold, 1960).

Robert L. Moore lebih jauh mengembangkan konsep ritus dari Van Gennep dan Turner, dalam konteks transformasi kesadaran manusia menuju kesadaran lain. Moore menyatakan bahwa proses ritual meniscayakan tiga aspek, yakni submission (penyerahan diri), containment (tapabrata, pelepasan diri), dan enactment (deklarasi pada kondisi berbeda) (Moore, 2001, hal. 107112). Artinya, dalam sebuah ritual terjadi transformasi pada pelakunya. Fenomena seperti ini dapat terjadi pada komunitas mana pun, termasuk ritual ruwatan rambut gimbal di wilayah Dieng, Jawa Tengah. Uraian di bawah ini merupakan usaha untuk menjelaskan fenomena keagamaan dalam konteks sosial-budaya manusia, dari perspektif teori-teori ilmu sosial dan humaniora.

Kajian tentang ritual ruwatan rambut gimbal di Dieng telah menjadi perhatian yang serius dari para sarjana dengan berbagai perspektif yang sangat beragam. Ritual ruwatan rambut gimbal menjadi fenomena yang menonjolkan aspek ritual itu sendiri. Ritual dimaknai sebagai sebuah proses negosiasi antar identitas kultural dengan inovasi-inovasi kultural pula, terutama pada aspek pariwisata. Kajian tentang ruwatan rambut gimbal terbagi menjadi tiga corak: pertama, prosesi ruwatan (ritual) itu sendiri; kedua, penajaman pada beberapa perspektif teoritis keilmuan seperti antropologi, psikologi, sosiologi, dan lain sebagainya; dan ketiga, kajian yang fokus pada korelasinya dengan wacanawacana baru seperti pariwisata. 
Kajian-kajian corak pertama lebih fokus pada tradisi atau prosesi ritualnya dengan pendekatan-pendekatan yang bervariasi. Eka Satria memfokuskan kajian semiotika budaya pada prosesi ruwatan (Satria, 2017; Yuliyanto \& Abidin, 2016). Kajian dengan tema yang serupa dilakukan oleh Nor Holis yang melihat prosesi ruwatan dengan pendekatan mitis (Holis, 2019).

Kemudian corak kajian kedua terfokus pada fenomena ritual yang dikaji dengan pendekatan teoritis yang lebih tajam. Secara Antropologis, rambut gimbal dapat dilacak secara garis keturunan dengan model genogram. Hal ini memberi penjelasan bahwa kemunculan rambut gimbal didasarkan pada kecenderungan orang tuanya dalam memilih pasangan dalam satu daerah, sehingga memunculkan runtutan genealogis anak berambut gimbal ke generasi setelahnya (Rahma, 2019). Kajian lain menguraikan konsep negosiasi budaya dengan inovasi-inovasi kultural yang dilakukan oleh masyarakat terkait ruwatan rambut gimbal tersebut (Luthfi, Prasetyo, Fatimah, \& Pularsih, 2019), atau kajian yang fokus melihat social teaching pada ritual rambut gimbal dengan perspektif Psikologi Sosial yang dikaitkan dengan aktifitas dakwah (Hidayah, 2019). Fenomena ruwatan rambut gimbal juga dikaji dari perspektif yang spesifik teori-teori Pendidikan Anak Usia Dini untuk melihat pola perilaku anak yang berambut gimbal (Mutmainah, 2012).

Corak ketiga dari kajian terhadap fenomena rambut gimbal melihat bagaimana korelasi prosesi ruwatan rambut gimbal dengan proses komodifikasi budaya dalam konteks pariwisata dari perspektif yang interdisipliner. Kajian yang dilakukan oleh Alfian Febriyanto, Selly Riawanti, dan Budhi Gunawan misalnya menyoroti aspek pelaku pada proses pergulatan identitas budaya dan transformasinya pada konteks yang lebih praktis sebagai komoditas pada level-level meso (masyarakat, pemuda) dan makro (pemerintah) (Febriyanto, Riawanti, \& Gunawan, 2017; Pularsih, 2015). Kajian lain yang dilakukan oleh Moh Soehadha lebih spesifik pada korelasi antara relijiusitas masyarakat dengan konstruksi mentalitas akan derasnya arus pariwisata yang menjadi salah satu pilar ekonomi di kawasan tersebut (Soehadha, 2013).

Secara spesifik kajian-kajian tersebut belum menyentuh persoalan makna pada prosesi ritual ruwatan rambut gimbal dari perspektif teori rites of passage Arnold van Gennep dan teori liminality dari Victor Turner. Dengan demikian kajian pada artikel ini merupakan pendalaman analisis dari kajiankajian yang telah dilakukan sebelumnya sebagai enrichment kajian atas ruwatan rambut gimbal di Dieng. 


\section{Metode}

Tulisan ini merupakan hasil riset lapangan (filed research). Sebagaimana telah diuangkapkan di pendahuluan, persoalan utama riset ini adalah sebuah tradisi ruwatan rambut gimbal yang dilakukan oleh masyarakat dataran tinggi Dieng. Tradisi ini megakar pada tradisi utama di pusat tradisi Jawa di Kraton Ngayogyokarto Hadiningrat. Dieng merupakan wilayah cultural periphery sedangkan kraton center of cultures. Terdapat konteks yang berbeda antara center dan periphery, dan tentu akan berdampak pada proses budaya yang berbeda sekaligus unik. Bagaimana relasi ini dapat dijelaskan? Inilah pertanyaan utama riset ini.

Sebagai objek kajian religi dan budaya, relasi tersebut terbentuk pada pola ritual yang dilakukan. Secara substanstif, prosesi ritual mengacu pada center of cultures yakni devotion to the Supreme Being yang disimbolkan dengan berbagai aspek ritual, dari ubo rampe sampai pemaknaanya. Dengan demikian, seluruh data dalam riset ini bersifat kualitatif. Data dikumpulkan dengan menggunakan metode observasi terlibat dengan mengamati langsung seluruh prosesi ritual. Kemudian wawancara dilakukan kepada pihak-pihak terkait seperti subjek/pelaku ritual, masyarakat sekitar pelaku, tokoh-tokoh masyarakat dan agama, praktisi kesehatan dan dokter, pemangku kebijakan/pemerintah desa sampai kabupaten. Selain itu data juga dikumpulkan dengan menelusuri sumber-sumber dokumen seperti laporan penelitian, jurnal-jurnal, buku-buku, serta sumber lain yang relevan dengan subjek kajian. Pengumpulan data juga dilakukan dengan focus group discussion (FGD) dari berbagai pihak yang terkait dengan subjek riset, seperti tokohtokoh, masyarakat sekitar, ormas keagamaan, dan lain sebagainya.

Analisis data dilakukan dengan mengaplikasikan pendekatan Fenomenologi Agama dan Antropologi Agama. Secara spesifik, teori Sacred and Prophane dari Mircea Eliade dalam Fenomenologi Agama digunakan untuk menganalisis konsep-konsep kesucian dalam seluruh fenomena ritual ruwatan. Kemudian, teori rites of passage dari Arnold van Gennep dan Victor Turner diaplikasikan untuk menjelaskan "inner discipline" dalam seluruh prosesi ritual ruwatan dan pemaknaannya. Teknik analisis dilakukan dengan mengklasifikasi data yang relevan, kemudian menyusun mengkorelasikan seluruh variabel utama riset dengan teori, selanjutnya menginterpretasikan secara mendalam makna yang terkandung dalam seluruh ritual. Akhir analisis data dimunculkan dalam bentuk simpulan yang menjawab permasalahan utama riset ini. 


\section{Pembahasan}

\section{Anak Bajang dan Mitos Rambut Gimbal}

Dilihat dari perspektif Sosiologi Agama seluruh aktivitas manusia selalu terkait dengan agama, dan muncul dalam bentuk-bentuk manifestasi yang sangat kompleks (Berger, 1966; Wach, 1958). Manifestasi pengalaman keagamaan itu meniscayakan adanya tautan "religious" untuk mempertegas bahwa fenomena yang nampak merupakan derivasi dari kesadaran terdalam dari the sacred -meminjam istilah Mircea Eliade (Eliade, 1961). Kehadiran the sacred dalam realitas manusia senantiasa ditafsirkan sesuai dengan konteks sosial dan budayanya. Untuk itulah Trevor Ling mengemukakan bahwa "a fair and impartial study of religious traditions means the study of their actual historical records in term of the ideas they teach..."(Ling, 1968, hal. xviii). Interpretasi atas Yang Suci terbatas pada kemampuan manusia mengartikulasikannya dalam lokalitas budayanya, sehingga kehadiran Yang Suci tersebut tidak sepenuhnya tertangkap oleh kapasitas budaya manusia, inilah yang disebut dengan ganz andere (Eliade, 1961). Di sinilah manusia menciptakan mitos sebagai salah satu manifestasi dan artikulasi kehadiran the sacred, yang muncul dalam bentuk narasi besar tentang kehidupan nenek moyang. Mitos-mitos itu kemudian diartikulasikan dalam bentuk simbolsimbol yang dibangun dari lokalitas budaya setempat, misalnya dengan menggambarkan dalam bentuk benda-benda atau peristiwa fenomenal yang terjadi dalam keseharian.

Fenomena mitos ini juga dapat ditemukan di masyarakat dataran tinggi Dieng, yang sebagian besar hidupnya diwarnai dengan mitos tentang kehidupan nenek moyang mereka. Dieng merupakan wilayah yang berada di cekungan besar Pegunungan Perahu di atas ketinggian $2150 \mathrm{M}$ dari permukaan air laut. Kondisi alam seperti ini mempunyai fluktuasi cuaca yang ekstrim. Suhu udara mencapai $8^{\circ}-10^{\circ} \mathrm{C}$ dan bahkan ketika bulan Juli-Agustus suhu mencapai $0^{\circ} \mathrm{C}$. Dataran tinggi Dieng berada di dua wilayah kabupaten, yakni Kabupaten Banjarnegara (Dieng Kulon) dan Kabupaten Wonosobo (Dieng Wetan dan Karang Tengah). John Lewis mengemukakan bahwa kesadaran agama selalu dibentuk oleh lokalitas masyarakatnya (Lewis, 1968). Dalam hal ini, dua wilayah kabupaten ini memiliki basis sejarah yang berbeda, sehingga melandasi struktur budaya masyarakat yang berbeda pula. Struktur budaya di samping dikonstruksi oleh struktur pemikiran juga oleh sejarah. Kompleksitas relasi antara budaya, sejarah, dan pemikiran akan membentuk sistem keyakinan. Inilah fenomena budaya di Dieng. 
Salah satu mitos yang sangat menonjol di wilayah Dieng adalah anak yang berambut gimbal. Mitos ini dibangun di atas dasar cerita masa lalu masyarakat Dieng awal. Asal-usul anak yang berambut gimbal oleh masyarakat diyakini secara bervariasi. Pertama, merupakan titipan dari Nyai Roro Kidul; kedua, keturunan Kiai Tumenggung Kaladete dan Nyi Roro Ronce; ketiga, keturunan dari Mbah Rewok, seorang muslim dari India. Variasi-variasi mitos yang dibangun akan dinarasikan secara detail dalam pembahasan tersendiri.

Rambut gimbal yang muncul pada anak tidak tumbuh sejak lahir, tetapi rata-rata baru muncul mulai usia 40 hari sampai 2 tahun. Munculnya rambut gimbal sebelumnya ditandai dengan demam tinggi selama beberapa hari atau bahkan sampai sebulan. Menurut masyarakat Dieng, untuk mengatasi demam tersebut pengobatan secara medis hanya efektif tiga atau empat hari saja, setelah itu demam muncul kembali. Demam akan hilang dengan sendirinya pada saat diketahui terdapat rambut gimbal. Menurut kepercayaan masyarakat Dieng, dengan tumbuhnya rambut gimbal perilaku anak sedikit berubah, relatif lebih nakal dan manja. Apa saja keinginan anak akan dipenuhi oleh orangtuanya, bahkan sang anak diperlakukan secara istimewa karena diyakini sebagai titisan Tumenggung Kaladete yang akan mendatangkan berkah. Anak ini kemudian disebut anak bajang, artinya anak yang mempunyai keistimewaan dan harus diperlakukan secara istimewa pula. Oleh karena itu, untuk mengembalikan sang anak kepada asal-usulnya perlu diadakan ruwatan, sebuah ritual yang secara khusus diadakan untuk memotong rambut gimbal oleh pemimpin spiritual desa, setelah permintaan sang anak dapat dipenuhi.

Di dalam kajian Sosiologi Agama, mitos ini merupakan "canopy dan paramount" bagi keyakinan sebagian masyarakat Dieng, yang selanjutnya akan mempengaruhi pola-pola keberagamaan mereka (Berger, 1966). Proses objektivasi keyakinan ini akan menjadi katalisator bagi manifestasi mitos dalam tradisi lisan (mentifact) yang pada gilirannya akan menstimulasi lahirnya ritus-ritus yang terkait dengan mitos tersebut. Manifestasi dari mitos dalam berbagai cerita dan dongeng suci itu akan berdampak secara langsung pada kehidupan sosial masyarakatnya (sociofact). Oleh karena itu, mitos tentang rambut gimbal membawa sositas mayarakat Dieng pada satu fase sejarah yang disebut dengan archetype -istilah dari Gustav Jung, yakni sebagai produk yang tak pernah berubah dari ketidaksadaran kolektif (Samuel \& Thompson, 1993, hal. 49). Meskipun demikian, mitos ini selalu menjadi legitimasi bagi aktivitas sosialnya (Chon, n.d., hal. 16), sehingga dalam penceritaannyapun fungsi ini sangat mewarnai, tidak terkecuali mitos tentang anak bajang berambut gimbal. 
Masyarakat di beberapa desa wilayah Dieng, seperti Dieng Kulon, Dieng Wetan, Karang Tengah, dan Sikunang misalnya, juga beberapa desa di lereng Gunung Sindoro dan Sumbing, seperti Desa Sidorejo di Kecamatan Parakan, Temanggung, mempunyai pandangan berbeda terhadap eksistensi anak bajang dan mitos yang mengelilinginya. Hal ini banyak dipengaruhi oleh pergesekan antara pandangan keagamaan masyarakat. dalam hal ini Islam, dengan tradisi Jawa. Berbagai varian pandangan mitos tentang rambut gimbal akan dinarasikan sebagai berikut berdasarkan wawancara dari tokoh masyarakat, tokoh agama, tokoh dan masyarakat awam,

Versi pertama, bahwa anak bajang atau anak berambut gimbal merupakan keturunan langsung dari Kiai Tumenggung Kaladete dan Nyai Roro Ronce. Ini merupakan narasi dari tradisi lisan yang bersumber dari cerita rakyat terutama di Dieng Kulon. Pada awalnya Tumenggung Kaladete merupakan pembesar di lingkungan Kraton Yogyakarta. Kemudian dia pergi ke Dieng dan mulai membuka lahan untuk wilayah perkampungan. Karena kondisi alam sedemikian dingin sehingga susah untuk lahan pertanian, maka Tumenggung Kaladete bersumpah untuk membiarkan dirinya kumal dan berambut gimbal, serta tidak akan mandi sebelum daerah ini makmur sejahtera. Sampai meninggal dunia sumpah itu tetap dipegang sehingga anak cucu Tumenggung Kaladete juga berambut gimbal. Anak-anak yang berambut gimbal diyakini sebagai anak turun Tumenggung Kaladete yang akan membawa berkah bagi keluarga, maka harus diperlakukan istimewa. Untuk menghilangkan rambut gimbal pada anak itu harus diadakan ritual khusus dengan melibatkan roh-roh penunggu berbagai tempat di wilayah Dieng, seperti Tuk Bimo Lukar, Telaga Warna, Gua mandalasari dan lain sebagainya. Oleh karena itu, ritual menjadi sangat urgen bagi kemakmuran wilayah Dieng.

Versi kedua, agak sedikit ada persamaan dengan versi pertama, tetapi Kiai Tumenggung Kaladete pada mulanya adalah pejabat keraton yang beragama Islam dan ke Dieng dalam rangka menyebarkan Islam. Setelah berhasil masuk Dieng Kiai Kaladete membuat wilayah Dieng Islam dengan membuat sistem "benteng". Di sebelah timur ditempatkan Kiai Selomanik di Desa Kali Terban, di sebelah barat ditempatkan Kiai Mangkuyudho di Desa Karang Tengah, di sebelah Selatang ditempatkan Kiai Girik di Desa Sigunung, sedangkan Kiai Kaladete sendiri berada di Dieng di Pesantren Kalibeber, sebagai pusat masyarakat muslim. Keberadaan para pemuka umat Islam tersebut sangat disegani karena di samping mempunyai daya linuwih juga langsung berhubungan dengan tokoh muslim dari India Syeh Gegeha Abdullah 
Hariri yang makamnya ada di Dieng. Sepeninggal para tokoh muslim tersebut keberadaan mereka yang semula disegani, kemudian dipuja, lalu dijadikan asal primordial masyarakat Dieng sebagai "leluhur abadi". Mereka adalah cikal bakal masyarakat Dieng, terutama Kiai Kaladete, sehingga keberadaannya melebihi masyarakat lainnya. Oleh karena itu, lahirlah keyakinan dan mitos sebagaimana diuraikan pada versi pertama, bahwa anak-anak yang berambut gimbal merupakan keturunan langsung dari Kiai Kaladete yang juga berambut gimbal karena sumpahnya.

Versi ketiga, anak-anak yang berambut gimbal merupakan titisan dari Nyai Roro Kidul, ratu penguasa laut selatan. Para anak yang berambut gimbal dipilih oleh penguasa laut selatan itu untuk memberi kemakmuran Dieng. Keberadaan anak bajang itu berada di bawah asuhan para roh penunggu wilayah dataran tinggi Dieng, juga wilayah dataran tinggi lain di pegungungan Sindoro dan Sumbing. Untuk segera mendatangkan kemakmuran, keberkahan, dan kesejahteraan bagi masyarakat, terutama keluarga anak yang berambut gimbal, rambut gimbal harus dikembalikan kepada Nyai Roro Kidul melalui ritual ruwatan khusus.

Ritual ruwatan merupakan acara kunci dan akhir bagi keseluruhan mitos tentang rambut gimbal. Ruwatan dilakukan setelah anak berusaia sekitar 5 tahun dan bersedia untuk dipotong rambutnya. Acara ini dilakukan secara meriah di rumah anak bajang dan melibatkan seluruh warga desa. Meskipun demikian, acara ruwatan juga dilakukan secara massal yang dikoordinasi oleh panitia khusus yang bekerja sama dengan pemerintah daerah, dalam hal ini Dinas Pariwisata, serta instansi swasta. Berbagai versi tentang anak bajang dan mitos yang mengelilinginya pada saat ritual ruwatan menyatu dalam ritual yang seragam. Ada sedikit perbedaan dalam beberapa fase ritual antara ritual yang dilakukan sendiri dengan yang dilakukan secara massal. Hal ini disebabkan adanya faktor di luar ritual yang telah masuk ke ranah ritus, seperti kepentingan pariwisata.

Selain tinjauan dari segi budaya, fenomena rambut gimbal juga dapat dijelaskan dari sisi medis. Menurut penjelasan tenaga medis Puskesmas Dieng, pada saat seseorang demam karena adanya infeksi di dalam tubuh, terjadi reaksi tubuh antara zat-zat kimiawi tubuh dengan enzim-enzim. Salah satu efek dari reaksi kimiawi itu adalah peningkatan kerja enzim prostaglandin sebagai mediator kimiawi, sehingga meningkatkan suhu tubuh dan demam. Kisaran kenaikan suhu sangat tergantung oleh kerja enzim prostaglandin tersebut. Demam dengan suhu tubuh antara $36-37,5^{\circ} \mathrm{C}$ termasuk kategori 
demam sub-febris dan tidak menyebabkan dampak sekunder, sedangkan apabila suhu tubuh di atas $37,5^{\circ} \mathrm{C}$ maka masuk dalam kategori demam febris yang akan menyebabkan dampak sekunder pada sesorang tersebut, misalnya kejang, mengigau, kulit luar mengelupas (ngglodoki). Untuk konteks rambut gimbal, ada faktor eketernal yang juga menjadi pemicu munculnya rambut gimbal.

Wilayah Dieng yang berada di ketinggian lebih dari 2000 meter di atas permukaan laut memiliki kelembaban udara sangat tinggi dan suhu sangat dingin. Pada saat anak menderita demam febris terjadi pertemuan suhu yang sangat ekstrim, panas dari dalam tubuh penderita dan dingin dari luar tubuh. Bersamaan dengan demam febris tersebut, terjadi reaksi di luar tubuh yakni menggumpalnya helai-helai rambut karena suhu eksternal yang dingin dan kelembaban udara yang tinggi. Meskipun demikian, hal ini tidak terjadi pada setiap anak yang mengalami demam febris, karena ada faktor lain yang turut mempengaruhi yakni faktor genetis dan faktor higenitas lingkungan. Ratarata anak yang berambut gimbal merupakan keturunan orang tua yang juga pernah berambut gimbal dan hidup dalam kondisi ekonomi yang terbelakang.

Pandangan budaya bahwa mitos telah menjadi "canopy" dari kesadaran masyarakat Dieng telah menggeser pandangan medis tersebut, sehingga ritual ruwatan memotong rambut gimbal berdampingan secara terpisah dengan pengobatan secara medis. Bronislaw Malinowski dalam buku Magic, Science and Religion (n.d., hal. 28), mengemukakan bahwa antara pandangan magis yang mempunyai tujuan untuk kegiatan dan peristiwa berikutnya mempunyai tingkat rasionalitas tersendiri, dan pandangan sains mempunyai juga rasionalitas sendiri-sendiri, yakni melalui pengobatan. Dengan demikian, kesadaran masyarakat Dieng tentang rambut gimbal juga harus dijelaskan dalam ranah rasionalitasnya sendiri-sendiri meskipun perlu penjelasan seacara terpisah. Perbedaan prinsipil dari pandangan magis dan mitis dengan pandangan saintis adalah tujuan ritualnya, jika ritual magis mempunyai tujuan untuk kegiatan dan peristiwa berikutnya, yakni keberkahan keluarga setelah di-ruwat, sementara pengobatan medis tujuannya adalah pengobatan itu sendiri. Oleh karena itu, jika mengacu pada Radcliffe-Brown rasa "ketidakberkahan" dan seandainya tidak dilakukan ritus ruwatan meniscayakan adanya ritus dari pandangan magis, dan ini tidak terjadi dalam pandangan medis atau saintis, sehingga ritual-ritual dalam pandangan magis menjadi sangat urgen (O'Dea, 1955, hal. 78). 


\section{Prosesi Ritual Ruwatan Rambut Gimbal}

Latar belakang munculnya pandangan mitis menurut Ernest Cassirer adalah penghadiran kembali pandangan intelektual yang primordial dengan simbolisasi kompleks dalam bentuk ritual (Cassirer, 1946, hal. 3-15). Bentukbentuk ritual meniscayakan kesadaran kolektif, karena di samping mempunyai tujuan "pengulangan sentimen primordial" dalam bentuk mitos, ritual juga menghadirkan solidaritas kelompok (O'Dea, 1955). Hal ini dilakukan karena prosesi ritual untuk menghadirkan kembali sentimen kolektif dalam mitos perlu keikutsertaan anggota kelompok secara kolektif pula, maka prosesi ritual harus dihadiri oleh seluruh anggota kelompok masyarakat. Dengan demikian, tindakan ritual kultus terhadap fenomena mitis merupakan tindakan sosial yang mempunyai makna bahwa kelompok sosial mempererat kembali hubungannya dengan hal-hal yang dianggap suci.

Ruwatan rambut gimbal merupakan salah satu bentuk ungkapan cult yang juga meniscayakan kehadiran komunitas sosial dalam seluruh rangkaian prosesinya. Sebagaimana telah diungkapkan di atas, bahwa tujuan ritus dan kultus merupakan penghadiran kembali sentimen primordial secara kolektif, maka ritual rambut gimbal lebih pada "tindakan magis-kolektif" untuk menghadirkan peristiwa berikutnya, yakni keberkahan bagi keluarga dan anggota kelompok dengan tetap juga mengembalikan pada kesadaran primordial pada Tumenggung Kaladete ataupun Nyai Roro Kidul. Oleh karena itu, seluruh rangkaian ritual dilakukan dengan menghadirkan kesadaran kolektif, meskipun diselenggarakan secara individu. Pelaksanaan ritual ini di bawah kendali pemimpin spiritual, yang oleh masyarakat Dieng disebut dengan lebai. Seorang lebai inilah yang menentukan dan mengatur seluruh rangkaian, prosedur ritual, alat-alat yang harus disiapkan, waktu ritual, dan siapa saja yang harus terlibat dalam inti ritual. Tampak sekali pengaruh Hinduisme masuk dalam prosesi ini. Hinduisme awal, terutama pada masa Brahmana, peran kaum brahmana begitu dominan sehingga ritual adalah brahmana itu sendiri (Lewis, 1968), atau bahkan tradisi shamanism (Bowie, 2000, hal. 190).

Untuk uraian seluruh prosesi ritual ruwatan akan dibagi dalam beberapa penjelasan, pertama, prosesi awal dan kelengkapan ritual, kedua, prosesi inti dan pemaknaan terhadap seluruh prosesi. Oleh karena itu, seluruh rangkaian akan dijelaskan sebagai berikut berdasarkan sumber-sumber lokal dari cerita lisan, observasi, dan wawancara dengan subjek ritual. 


\section{Prosesi Awal dan Kelengkapan Ritual}

Penentuan ritual ruwatan terhadap anak berambut gimbal adalah kesediaan anak untuk di-ruwat. Ada dua variasi penentuan, yakni si anak meminta untuk dipotong rambut gimbalnya atau orang tua meminta si anak untuk dipotong rambut gimbalnya. Keduanya tetap tergantung pada kesediaan si anak. Secara umum, variasi pertama yang lazim dilakukan, yakni si anak meminta untuk dipotong gimbalnya. Ini didasarkan pada adanya mitos tentang anak bajang yang harus diperlakukan secara istimewa, sehingga orang tua enggan memulai untuk meminta kesediaan si anak.

Setelah anak bersedia untuk dipotong rambutnya, akan ada satu persyaratan yang harus dipenuhi oleh orang tua yakni permintaan sesuatu oleh anak, dan orang tua harus mengabulkan permintaan itu. Permintaan anak bisa berupa barang mainan, makanan, atau binatang piaraan, serta alat-alat yang mahal seperti televisi. Terlaksananya upacara akan sangat tergantung pada kekuatan ekonomi untuk memenuhi permintaan anak. Apabila orang tua belum bisa memenuhi permintaan anak, maka besar kemungkinan ritual tertunda pelaksanaannya. Begitu sebaliknya, jika permintaan belum dapat dipenuhi tetapi ritual dilaksanakan, menurut keyakinan masyarakat Dieng, rambut gimbal akan tumbuh kembali meskipun sudah dipotong.

Jika semua telah dipenuhi, proses berikutnya orang tua si anak menghadap ke qayim atau lebai untuk meminta kesediaan memimpin ritual pemotongan rambut gimbal. Lebai kemudian menentukan waktu ritual yang dihitung sesuai dengan neptu/weton-hari lahir dalam penanggalan Jawa, misalnya Rabu Kliwon. Bila tidak sesuai dengan weton, maka pergeseran waktu disesuaikan dengan perhitungan karo-hari kedua setelah weton, yakni Jumat Pahing; atau kapat-hari keempat setelah weton, yakni Ngad Wage. Setelah waktu ditentukan, maka orang tua mempersiapkan ubo rampe (perlengkapan ritual) dasar yang terdiri dari beberapa ubo rampe, di antaranya tumpeng kalung, tumpeng robyong, tumpeng rasul, tumpeng putih, golong, ambeng, ingkung, dan jajan pasar. Kemudian peralatan yang disiapkan adalah baskom yang diisi dengan air dan kembang telon (bunga tiga jenis) yakni bunga mawar, bunga kanthil, dan bunga kenanga, tikar pandan, gunting untuk memotong, dan kain putih (mori) 


\section{Prosesi Inti dan Pemaknaan Ritus}

Setelah semuanya sudah siap, lebai akan memimpin seluruh prosesi, dengan urut-urutan acara sebagai berikut, yakni anak duduk tepat di depan lebai dengan posisi membelakangi lebai, posisi baskom yang berisi air dan kembang telon berada di sebelah kanan lebai, sedangkan perlengkapan ritual lainnya di letakkan di depan anak.

Kemudian lebai megelus-elus kepala anak dan memusat ke arah rambut yang gimbal. Dengan bacaan doa-doa tanpa suara, lebai mengurut-urut rambut yang gimbal dengan suasana yang sangat khidmat, dan setelah itu disebutlah satu persatu leluhur si anak - mulai dari orang tua, kakek nenek, dan seterusnya, sambil memotong beberapa helai rambut yang gimbal. Rambut yang telah dipotong diletakkan ke dalam baskom yang telah diisi air dan kembang telon. Kemudian lebai membaca doa dengan bersuara secara tradisi Islam, peserta ritual lainnya berdiri, dan anak berjalan berkeliling mengitari para hadirin.

Acara dilanjutkan dengan sambutan-sambutan dari tuan rumah, pengajian oleh tokoh agama, ramah-tamah, dan makan bersama -tuan rumah menyediakan berbagai macam makanan besar, seperti nasi dan kelengkapannya, serta makanan ringan dan kelengkapannya. Acara kemudian ditutup dengan membacakan doa keselamatan yang dipimpin oleh tokoh agama. Rambut kemudian di-larung (dihanyutkan) di Sungai Serayu, dengan harapan bisa terbawa kembali ke Laut Selatan, tempat Nyai Roro Kidul. Ritual yang diuraikan tersebut merupakan upacara yang dilaksanakan oleh warga secara individu sesuai dengan kebutuhan dan kemampuannya. Ada berbagai variasi pelaksanaannya di antara desa satu dengan lainnya, namun secara umum prosesi ritual hampir sama dengan uraian sebagaimana di atas.

Setelah dilaksanakan upacara ritual tersebut, terdapat kepercayaan di kalangan masyarakat Dieng bahwa rambut gimbal di kepala anak tidak lagi tumbuh, demikian juga perilaku anak juga berubah. Proses-proses inisiasi sebagaimana disebutkan di atas merupakan satu fenomena sosial-budaya yang mengakar pada pemahaman tentang keberadaan "The Sacred". Ungkapanungkapan pengalaman keberagamaan melalui media ritual menjadi penanda bahwa terdapat kesadaran tentang eksisitesi yang "Adi Kodrati" yang "mengayomi" kesadaran manusia. Hal ini dalam Sosiologi Agama disebut sebagai kultus (cult) (Eister, 1972, hal. 319-333; O'Dea, 1955). Kesadaran dan keadaan alamiah manusia merupakan keadaan yang tidak pasti dan kritis - 
meminjam istilah Berger, fragile and insecure, terlebih ketika berada pada masa peralihan tertentu, sehingga meniscayakan adanya upacara-upacara ritual untuk memuja Yang Suci dengan tujuan mengembalikan situasi kritis dan marginal pada kondisi "equilibrium dan harmony" baik secara individu maupun kolektif.

Di samping ritus-ritus yang dilaksanakan secara individual, ada juga ritus yang diselenggarakan secara kolektif. Untuk melihat fenomena itu variasi ritual yang dilakukan secara kolektif akan diuraikan berikut; pertama, Kelengkapan ritual hampir sama dengan prosesi individual, yakni, tumpeng kalung, tumpeng robyong, tumpeng kuning, tumpeng putih, tumpeng abang, tumpeng ireng, tumpeng panggung, golong, ambeng, ingkung, jajan pasar. Kedua, prosesi, agak sedikit berbeda dengan prosesi yang individual, karena semua ditangani oleh panitia lokal, Dinas Pariwisata Pemerintah Propinsi Jawa Tengah, dan sponsor. Penyelenggaraan acara tidak memperhatikan neptusi anak bajang, tetapi dilaksanakan dalam acara yang khusus diadakan, untuk acara ini bersama gelar budaya Dieng sebagai bentuk komoditas pariwisata -biasanya pada Bulan Agustus bersama peringatan Hari Ulang Tahun Republik Indonesia, atau hari libur lainnya.

Ketiga, kronologi prosesi ruwatan rambut gimbal secara kolektif sebagai berikut: (1) Panitia mencari anak yang bersedia di-ruwat rambut di wilayah dataran tinggi Dieng (Dieng Kulon, Karang Tengah, Sikunang, dan lain sebagainya). Di dalam pencarian ini panitia sekaligus menginventarisir keniginan si anak. (2) Kemudian anak dikumpulkan di rumah tokoh spiritual Dieng, Ki Rusmanto, untuk didoakan secara magis oleh tokoh spiritual. Sebelum melakukan tugas ini, pemimpin spiritual melakukan laku spiritual ke Tuk Bimo Lukar, ke Gunung Kendil untuk caos dhahar (memberi persembahan pada roh-roh ghaib), dan berakhir di Pertapaan Mandalasari Gua Semar untuk melakukan samadi memohon ijin dan petunjuk pada rohroh leluhur. Keesokan harinya pemimpin spiritual baru turun melakukan tugas sebagai tokoh spiritual dalam ruwatan rambut gimbal tersebut. (3) Kemudian para anak bajang di mandikan dan dikeramasi di Sendang Maerokoco dan Sendang Sedayu dengan menggunakan banyu kembang telon (air yang dicampur bunga tiga warna -bunga mawar, kanthil, dan kenanga), kemudian anak diistirahatkan di Darmasala (salah satu situs Candi Dieng). (4) Kemudian dilakukan kirab menuju Gua Batu Tulis, anakanak bajang diselimuti dengan kain putih, yang sebelumnya diadakan 
beragai macam pertunjukkan seni, seperti Tari Topeng Rampak Yaksa, Tettek, Lasykar Aswatama, Barongsai, dan Reog. (5) Di Batu Tulis inilah puncak acara ruwatan dilaksanakan. Seluruh perlengkapan dan ubo rampe ritual disiapkan, acara kemudian dimulai dengan protokol formal karena ada bermacam sambutan. Warga Dieng lazim menamakan acara ini dengan selamatan massal. Anak-anak bajang didudukkan berdekatan dengan barang-barang permintaan masing-masing, dan mereka diminta untuk memilih makanan apa saja yang disediakan oleh panitia. (6) Acara berikutnya adalah ritual puncak, masing-masing anak didoakan secara magis dan helai-helai rambut gimbal dipotong oleh pemimpin spiritual. Masing-masing potongan diletakkan di dalam baskom kecil yang berisi air kembang telon. (7) Kemudian potongan-potongan rambut tersebut dibungkus dengan kain putih, lalu dilarung ke Telaga Warna bersama dengan Tumpeng kalung dan seluruh rangkaiannya berupa hasil bumi.

\section{Reagregasi Sistem Budaya}

Seluruh rangkaian acara dilaksanakan pada siang hari secara meriah dengan menonjolkan aspek pariwisata. Berbagai objek wisata di wilayah Dieng disertakan sebagai bagian dari seluruh rangkaian acara ruwatan. Di sinilah apa yang diungkapkan oleh Arnold van Gennep dan Victor Turner tentang rites of passage menjadi sangat penting. Baik van Gennep maupun Turner melihat adanya kesinambungan antara proses ritus dan "kesadaran agama". Artinya, ketika ritus dan pemujaan dilakukan pada hakikatnya komunitas tersebut sedang melakukan transformasi kesadaran menuju harmony, dan ini sangat terkait dengan konteks tertentu yang dalam hal ini adalah situs tujuan wisata di Dieng. Meskipun demikian, secara antropologis makna ritual itu tidak sesempit yang biasa dipahami sebagai ritus-ritus yang dilakukan secara periodik, tetapi jauh melampaui pemahaman tentang ritual itu sendiri yakni persoalan perubahan dan perkembangan (change and development). Arnold van Gennep dalam Rites of Passage,sebagaimana dikutip oleh Fiona Bowie, mengkonsepkan ritual sebagai sebuah runtutan proses yang berfungsi,

... for transition rituals, making change of status, whether persons or seasons, collective or individual, ...that all of rites of passage have a threefold structure. The first stage is that of separation from the previous state, place, time, or status. The follows a middle stage, which is neither one thing nor the other, before the final stage of reintegration, but in a transformed condition. The basic pattern can be discern [sic!] within almost all rituals, particularly if they mark some type of transition or movement...(Bowie, 200o) 
Berangkat dari fungsi dan tujuan ritual itu, maka proses peralihan dalam sebuah masyarakat secara minimal juga dapat dikategorikan sebagai hal yang identik dengan ritual-ritual dalam arti umum. Logika inilah yang dijadikan landasan konseptual dari ritual dalam proses yang dikemukakan oleh van Gennep, sebagaimana dikutip Bowie, bahwa proses transformasi secara umum melewati tiga fase: separasi (pemisahan struktural), prosesi, yang merupakan struktur peralihan, dan reintegrasi (restrukturisasi masyarakat dengan justifikasi nilai yang baru) (Ball, 1988, hal. 26; Bowie, 2000). Fase-fase yang menggambarkan fungsi dan status proses transformasi dalam masyarakat menunjukkan identifikasi yang tinggi terhadap proses tripartite [separasi, transisi, reagregasi] dalam menuju equilibrium dan harmony.

Turner mengembangkan rites of passage dari van Gennep, yakni pada fase peralihan (transisi). Teori dikembangkan dari riset yang dilakukan di kalangan suku Ndembu di Zambia, Afrika. Turner memang berangkat dari bentuk-bentuk ritual di dalam masyarakat Ndembu, tetapi setelah mengkonstruk konsep komunitas [Lt. communitas, Ing. community] sebagai satuan sositas, Turner membuat generalisasi terhadap unsur-unsur komunitas dalam sositas tertentu (Turner, 1991). Komunitas yang dimaksudkan adalah sositas yang berada dalam fase liminal yang telah berpisah secara struktur sosial tetapi belum sampai pada sositas baru. Di dalam rites of passage, terjadi transformasi budaya dari berstruktur menuju anti struktur dan kembali lagi pada struktur, sementara komunitas muncul dari fase yang tidak berstruktur sama sekali, sehingga lahir tipifikasi [klasifikasi] komunitas didasarkan pada faktor struktur yang melekat bersamanya (Turner, 1991). Klasifikasi itu antara lain, normative communities, existential communities, dan ideological communities. Masing-masing communitas terkait dengan faktor struktur yang berbeda, ketika sebuah komunitas muncul sebagai fase dari ritual yang egaliter dan sama sekali tidak berstruktur disebut dengan konsep komunitas asli, atau makna asli dari konsep communitas. Adapun jika muncul sebagai respon terhadap struktur dan menempati fase anti-struktur, maka itulah komunitas eksistensial (spontan), misalnya komunitas petani kentang, penjual pupuk, seni Rampak Yaksa dan lain-lain, tetapi ketika dalam lingkup tempus tertentu harus mengorganisir anggota komunitas dengan tujuan-tujuan tertentu maka komunitas tersebut merupakan wujud dari komunitas ideologis, misalnya organisasi petani kentang, penjual pupuk, seni Rampak Yaksa yang telah memiliki ketua, anggota dan sebagainya. 
Kembali pada pokok persoalan semula, bahwa dalam proses rites of passage terjadi dialektika antara struktur dan anti-struktur, sehingga sebuah proses perubahan sosial juga merupakan dialektika struktur. Oleh karena itu, seperti ditegaskan oleh Bowie, fase peralihan selalu mengandaikan adanya ambiguitas status, sehingga meniscayakan proses inisiasi dimana inisian [atau istilah khusus Turner, neophyte/initiand] "is reshaped or molded physically and psychologically so that society's values can be inscribed on his or her body and mind"(Bowie, 2000). Karakteristik khas masyarakat liminal menurut Turner sebagai berikut,

Liminal entities are assigned and arrayed by law, custom, convention, and ceremonial. As such, their ambiguous and indeterminate are expressed by a variety of symbols in the many societies that ritualized social and cultural transitions (Turner, 1991).

Kemudian munculnya inisian-inisian dalam fase peralihan itu memposisikan komunitassebagai entitas yang memiliki privileges yang memediasi dua kutub sosial budaya yang saling berlawanan. Pola-pola peralihan dari tradisi ritual ruwatan rambut gimbal tampak pada prosesi yang menggambarkan perjalanan "spiritual" menuju fase "kebebasan" dari kondisi titipan nenek moyang. Kalau mengacu pada kerangka teoritis di atas, prosesi ruwatan rambut gimbal dapat dilihat sebagai sebuah perjalanan komunitas satu entitas anak-anak berambut gimbal, melalui fase-fase ritus yang kesemuanya menuju kondisi yang menyatu dengan kesadaran masyarakat yang aman dan damai. Oleh karena itu, selain ritus-ritus inti yakni pemotongan rambut, ada ritus-ritus lain yang merupakan fase separasi misalnya laku spiritual, caos dhahar, dan semedi; dan fase reagregasi -yaitu ritus pelarungan rambut dan doa-doa yang menyertainya. Pada fase separasi, shaman (lebai) berusaha mengkondisikan suasana ritual ruwatan terpisah dari kesadaran umum masyarakat, dan hal ini dilakukan secara magis. Pandangan magis secara perlahan akan melepaskan kesadaran umum, common sense menuju pada kesadaran ritus dan kultus yang berada di wilayah the sacred (Otto, 1923). Oleh karena itu, secara simbolik shaman berkomunikasi secara magis kepada apa yang dianggap suci dengan semedi dan memberi persembahan berupa sesaji.

Fase inisiasi yakni pemotongan rambut yang menjadi puncak ritual ruwatan menjadi satu kondisi yang insecure -antistruktur menurut Turner, sehingga memerlukan satu justifikasi nilai supaya bermakna sebagai bentuk inisiasi dari satu fase kehidupan ke fase berikutnya. Kalau Berger melihat 
bahwa bentuk justifikasi yang paling utama adalah "agama", maka bagi Turner dalam fase liminal ini kesatuan entitas anak bajang dijustifikasi dengan bentuk ideological communities. Ideologi yang ditemukan dalam fase liminal Turner lebih pada bentuk justifikasi nilai bahwa ada satu entitas nilai yang melandasi "antistruktur"-nya komunitas yaitu tujuan-tujuan magis ritual itu sendiri. Tanpa ada tujuan magis, secara ideologis ritual akan terhenti pada proses pemotongan saja, sehingga anak-anak bajang hanya bisa dikatakan sebagai komunitas rambut gimbal dalam arti yang asli (normative communities).

Fase reagregasi ditandai dengan upaya menghanyutkan (melarung) sumber kesialan dan mengirimkan kembali pada asal primordial rambut gimbal -Kiai Tumenggung Kaladete atau Nyai Roro Kidul. Fase ini hakikatnya ingin membangun satu struktur sosial yang baru bahwa anak bajang bisa diterima sebagai anak yang hidup normal, tidak lagi di bawah kekuasaan "primordialisme magis". Dengan demikian, kesadaran sosial yang dibangunpun mengacu pada kondisi objektif komunitas anak bajang dengan jalan menerima kembali sebagai satu kesatuan kolektif masyarakat Dieng.

Ada satu fenomena percampuran budaya yang "unique" dalam ritus yang dilaksanakan secara kolektif ini, yakni antara tradisi dan kepentingan materi. Ernest Troeltsch mengungkapkan bahwa ketika "tradisi suci" berhadapan dengan "tradisi profan", atau istilah Troeltsch - gereja dan dunia, yang terjadi adalah kompromi atau penolakan (O'Dea, 1955). Kemungkinankemungkinan akan selalu terjadi sejauh persentuhan dan penilaian-penalaian antara keduanya. Ritual ruwatan rambut gimbal lebih menunjukkan proses kompromi yang positif ketika tradisi ini masuk dalam agenda pariwisata pemerintah daerah Banjarnegara dan Wonosobo. Kalau ditelisik secara mendalam, menurut Samuelson (1964, hal. 19) pada hakikatnya agama yang mengusung tradisi yang suci menolak pola-pola kapitalisme budaya seperti yang terjadi di Dieng, tetapi karena ada faktor afinitas budaya dalam agama maka pergeseran itu tetap menjadi bagian sikap kompromis. Oleh karena itu, selain ritual yang dilakukan secara individu ada variasi lain, yakni ritual secara kolektif. Secara prinsip prosesi hampir sama, tetapi karena bercampur dengan unsur-unsur pariwisata maka terdapat unsur showing and exibition fase demi fase dari rangkaian ritual.

Sikap kompromis yang dilakakukan oleh pemangku adat terhadap masuknya aspek pariwisata tidak dinilai sebagai "penodaan" atas "kesucian" tradisi ruwatan rambut gimbal melainkan sebagai wujud cultural care pemerintah terhadap warisan budaya. Salah satu pemangku adat, Ki Naryono, 
justru menganggap showing up acara ruwatan ini sebagai penjagaan atas kesadaran primordial masyarakat Dieng dengan mempromosikan dan menampilkan dalam bentuk hiburan. Oleh karena itu, tanggapan umum masyarakat Dieng sangat positif terhadap cultural attitude dari pemerintah. Bagi masyarakat Dieng, acara ruwatan yang dilaksanakan secara kolektif dan ditayangkan secara massal oleh berbagai media, begitu juga didukung investasi yang besar akan menambah kesejahteraan hidup.

\section{Simpulan}

Mencermati uraian di atas dapat digambarkan bahwa ritual merupakan manifestasi atas konsep-konsep kesucian yang diyakini oleh masyarakat Dieng. Ritual ruwatan rambut gimbal merupakan salah satu dari berbagai manifestasi kebudayaan religius mereka. Sebagai masyarakat yang menempati wilayah periferi yang jauh dari pusat budaya Jawa -Kraton Ngayogyakarta Hadiningrat, penduduk Dieng menyelenggarakan ritual ruwatan rambut gimbal dengan improvisasi sesuai dengan konteks iklim dan kebudayaan (climate and culture) mereka.

Ritual yang dilakukan, sepanjang analisis dari perspektif rites of passage, menampilkan gambaran bahwa ritual ruwatan rambut gimbal memberi maknamakna baru bagi masyarakat periferi seperti Dieng. Di antara makna baru pada fase reaggregation atau enactment adalah kompromi positif antara konsep kesucian dengan konsep-konsep yang lebih "duniawi" seperti kepentingan pariwisata (ekonomi). Konsep kesucian tetap dipertahankan sebagai sistem budaya (religi) yang mempunyai determinasi nilai atas tindakan, namun juga diterjemahkan dalam konsep profan untuk dikompromikan dengan konteks pariwisata di kawasan Dieng. 


\section{Referensi}

Ball, J. van. (1988). Sejarah dan Pertumbuhan Teori Antropologi Budaya (Hingga Dekade 1970an). Jakarta: PT Gramedia.

Berger, P. L. (1966). The Sacred Canopy : Elements of a Sociological Theory of Religion. New York: One Road Media (Epub File).

Bowie, F. (2000). The Anthropology of Religion. Oxford: Blackwell Publishers.

Cassirer, E. (1946). The Myth of the State. New Heaven: Yale University Press.

Chon, N. (n.d.). The Myth of Satan and his Human Servants. In M. Douglas (Ed.), Witchcraft: Confessions and Accusations. London: Taylor \& Francis.

Eister, A. W. (1972). An Outline of a Structural Theory of Cults. Journal for the Scientific Study of Religion, 11(4).

Eliade, M. (1961). The Sacred and the Profane: The Nature of Religion. New York: Harper \& Row Publisher.

Febriyanto, A., Riawanti, S., \& Gunawan, B. (2017). Mitos Rambut Gimbal: Identitas Budaya dan Komodifikasi di Dataran Tinggi Dieng. UMBARA: Indonesian Journal of Anthropology, 2(1).

Geertz, C. (1966). Religion as A Cultural System. In Anthropological Approach to the Study of Religion, A.S.A. Monograph. London: Travistock Publications.

Gennep, A. van. (1960). The Rites of Passage. Chicago: University of Chicago Press.

Hidayah, U. (2019). Nilai-Nilai Sosial Dalam Budaya Ruwat Rambut Gembel di Desa Dieng Kulon Kecamatan Batur Kabupaten Banjarnegara. IAIN Purwokerto.

Holis, N. (2019). Tradition of Dreadlocks Shaving Ritual (Gimbal) in Dieng Plateau Wonosobo. Jurnal Metaphor, 1(1).

Lambek, M. (Ed.). (2002). A Reader in Anthropology of Religion. Oxford: Blackwell Publishers.

Lewis, J. (1968). Religions of the World Made Simple. NY: Doubleday and Company, Inc.

Ling, T. (1968). A History of Religion: East and West. London: Palgrave Macmillan.

Luthfi, A., Prasetyo, K. B., Fatimah, N., \& Pularsih, E. (2019). Ruwatan Ritual of Dreadlocks Haircut: Negotiation Between Cultural Identity and Cultural Innovation in Contemporary Dieng Plateau Community. In First International Conference on Advances in Education, Humanities and Language (ICEL). Malang: EAI. Retrieved from https://eudl.eu/doi/10.4108/eai.23-3-2019.2284905

Malinowski, B. (n.d.). Magic, Science and Religion, and Other Essays.

Moore, R. L. (2001). The Archetype of Initiation: Sacred Space, Ritual Process, and Personal Transformation. (M. J. Haflick \& Jr., Eds.). San Fransisco: XLIBRIS.

Mutmainah, S. (2012). Perilaku Sosial Anak Usia Dini Berambut Gimbal di Daerah Dataran Tinggi Dieng Kabupaten Wonosobo. Indonesian Journal of Early Childhood Education Studies, 1(1). 
O'Dea, T. F. (1955). The Sociology of Religion (Sosiologi Agama). Jakarta: Rajawali Pers.

Otto, R. (1923). The Idea of The Holy. London: Oxford University Pess.

Potz, M. (2020). Political Science of Religion : Theorising the Political Role of Religion. Switzerland: Palgrave Mcmillan.

Pularsih, E. (2015). Komodifikasi Ruwatan Massal Cukur RambutGembel Pada Festival Budaya Tahunan diDataran Tinggi Dieng Kabupaten Wonosobo. Universitas Negeri Semarang.

Rahma, A. M. (2019). Analisis Genealogi dan Mean Matrimonial Radius(Studi Pada Masyarakat Berambut Gimbal di Desa Dieng Wetan Kecamatan Kejajar Kabupaten Wonosobo). Universitas Airlangga.

Samuel, R., \& Thompson, P. (1993). The Myths We Live By. London and New York: Routledge.

Samuelson, K. (1964). Religion and Economic Action. New York and Evanston: Harper Torchbook.

Satria, E. (2017). Tradisi Ruwatan Anak Gimbal di Dieng. Jurnal Warna, 1(1).

Smith, M. (2008). Religion, Culture, and Sacred Space. New York: Palgrave Macmillan.

Soehadha, M. (2013). Ritual Rambut Gembel dalam ArusEkspansi Pasar Pariwisata. Jurnal Walisongo, 21(2).

Turner, V. (1991). The Ritual Process: Structure and Anti-structure. Ithaca, N.Y: Cornell University Press.

Wach, J. (1958). The Comparative Study of Religions. NY dan London: Columbia University Pres.

Williams, R. H. (2005). Religion as a Cultural System": Theoretical and EmpiricalDevelopments Since Geertz. In M. D. J. Hanrahan \& N. W. Hanrahan (Eds.), The BlackwellCompanion to theSociology of Culture. Oxford: Balckwell Publishing.

Yuliyanto, E. E., \& Abidin, Z. (2016). Ruwat Rambut Gembel. Jurnal Empati, 5(3). 